\title{
Coral responses to a repeat bleaching event in Mayotte in 2010
}

\author{
David O Obura ${ }^{\text {Corresp.., }}{ }^{1}$, Lionel Bigot ${ }^{2}$, Francesca Benzoni ${ }^{3}$ \\ ${ }^{1}$ CORDIO East Africa, Mombasa, Kenya \\ 2 UMR Entropie, Laboratoire d'écologie marine, Université de la Reunion, Saint Denis, Reunion \\ 3 Department of Biotechnology and Biosciences, University of Milano - Bicocca, Milan, Italy \\ Corresponding Author: David O Obura \\ Email address: dobura@cordioea.net
}

Background: High sea surface temperatures resulted in widespread coral bleaching and mortality in Mayotte Island (northern Mozambique channel, Indian Ocean: 12.1ㅇ, 45.1 $\mathrm{E}$ ) in April-June 2010.

Methods: Twenty three representative coral genera were sampled quantitatively for size class distributions during the peak of the bleaching event, to measure its impact.

Results. Fifty two percent of coral area was impacted, comprising $19.3 \%$ pale, $10.7 \%$ bleached, $4.8 \%$ partially dead and $17.5 \%$ recently dead. Acropora, the dominant genus, was the second most susceptible to bleaching (22\%, pale and bleached) and mortality (32\%, partially dead and dead), only exceeded by Pocillopora (32\% and $47 \%$, respectively). The majority of genera showed intermediate responses, and the least response was shown by Acanthastrea and Leptastrea ( $6 \%$ pale and bleached). A linear increase in bleaching susceptibility was found from small colonies $(<2.5 \mathrm{~cm}, 83 \%$ unaffected) to large ones ( $>80$ $\mathrm{cm}, 33 \%$ unaffected), across all genera surveyed. Maximum mortality in 2010 was estimated at $32 \%$ of coral area or biomass, compared to half that (16\%), by colony abundance.

Discussion. Mayotte reefs have displayed a high level of resilience to bleaching events in 1983, 1998 and the 2010 event reported here, and experienced a further bleaching event in 2016. However, prospects for continued resilience are uncertain as multiple threats are increasing: the rate of warming experienced $\left(0.1^{\circ} \mathrm{C}\right.$ per decade) is some $2-3$ times less than projected warming in coming decades, the interval between severe bleaching events has declined from 16 to 6 years, and evidence of chronic mortality from local human impacts is increasing. The study produced four recommendations for reducing bias when monitoring and assessing coral bleaching: coral colony size should be measured, unaffected colonies should be included in counts, quadrats or belt transects should be used and weighting coefficients in the calculation of indices should be used with caution. 


\section{Coral responses to a repeat bleaching event in Mayotte in $\mathbf{2 0 1 0}$}

3 Running title: Coral bleaching in Mayotte, 2010

5 David O. Obura ${ }^{*}$, Lionel Bigot ${ }^{2}$ and Francesca Benzoni ${ }^{3}$

\section{Author Addresses:}

8 1) CORDIO East Africa, Mombasa, Kenya.

9 2) UMR Entropie, Laboratoire d'écologie marine, Université de la Réunion, 15 Av. René Cassin

10 - 97715 - France - La Réunion

11 3) Dept. Biotechnology and Biosciences, University of Milano-Bicocca, 20126 Milan - Italy

14 * Corresponding author:

15 David Obura

16 Email address: dobura@cordioea.net 
19 ABSTRACT

20 Background: High sea surface temperatures resulted in widespread coral bleaching and

21 mortality in Mayotte Island (northern Mozambique channel, Indian Ocean: $12.1^{\circ} \mathrm{S}, 45.1^{\circ} \mathrm{E}$ ) in

22 April-June 2010.

23 Methods: Twenty three representative coral genera were sampled quantitatively for size class

24 distributions during the peak of the bleaching event, to measure its impact.

25 Results. Fifty two percent of coral area was impacted, comprising $19.3 \%$ pale, $10.7 \%$ bleached,

$264.8 \%$ partially dead and $17.5 \%$ recently dead. Acropora, the dominant genus, was the second

27 most susceptible to bleaching (22\%, pale and bleached) and mortality ( $32 \%$, partially dead and

28 dead), only exceeded by Pocillopora (32\% and 47\%, respectively). The majority of genera

29 showed intermediate responses, and the least response was shown by Acanthastrea and

30 Leptastrea (6\% pale and bleached). A linear increase in bleaching susceptibility was found from

31 small colonies ( $<2.5 \mathrm{~cm}, 83 \%$ unaffected) to large ones ( $>80 \mathrm{~cm}, 33 \%$ unaffected), across all

32 genera surveyed. Maximum mortality in 2010 was estimated at $32 \%$ of coral area or biomass,

33 compared to half that $(16 \%)$, by colony abundance.

34 Discussion. Mayotte reefs have displayed a high level of resilience to bleaching events in

351983,1998 and the 2010 event reported here, and experienced a further bleaching event in

36 2016. However, prospects for continued resilience are uncertain as multiple threats are

37 increasing: the rate of warming experienced $\left(0.1^{\circ} \mathrm{C}\right.$ per decade $)$ is some $2-3$ times less than

38 projected warming in coming decades, the interval between severe bleaching events has

39 declined from 16 to 6 years, and evidence of chronic mortality from local human impacts is

40 increasing. The study produced four recommendations for reducing bias when monitoring and

41 assessing coral bleaching: coral colony size should be measured, unaffected colonies should be

42 included in counts, quadrats or belt transects should be used and weighting coefficients in the

43 calculation of indices should be used with caution. 


\section{INTRODUCTION}

Coral bleaching is an increasingly common phenomenon on tropical coral reefs as background warming occurs and inter-annual modes of climate variability intensify (McPhaden et al. 2004; Hoegh-Guldberg et al. 2007). Repeated major coral bleaching events are now standard occurrence in most world regions (Donner et al. 2017, Hughes et al. 2018), including the Caribbean (Eakin et al. 2010; Jackson et al. 2014), the Pacific (Chin et al. 2011), and the western Indian Ocean (McClanahan et al. 2014, Obura et al. 2017), and recently in concurrent years on the Great Barrier Reef (Hughes et al. 2017b). The Western Indian Ocean (WIO) has suffered repeated bleaching events, with the most extreme being in 1998 (Wilkinson et al. 1999; Goreau et al. 2000), but with smaller events before, most notably in 1983 (Faure et al. 1984) and since, in 2005 (McClanahan et al. 2005), 2007 (DO, unpublished data), 2010 (Eriksson et al. 2012) and 2016 (Nicet et al. 2016, Obura et al. 2017). The increasing frequency of major bleaching events (Hughes et al. 2018) is calling into question the long term survival of coral reef ecosystems, with most world regions predicted to experience severe bleaching conditions on an annual basis within the next 40-80 years (van Hooidonk et al. 2016).

How well coral reefs will cope with these conditions is a major question in current research (Hughes et al. 2017a). The WIO was among the worst affected regions during the 1998 bleaching event. In that year three phenomena coincided - 1998 was an unusually hot year globally, and strong positive phases of the EI Niño Southern Oscillation (ENSO) and Indian Ocean Dipole (IOC) occurred in phase (Saji 2001; McPhaden et al. 2004). As a consequence, coral mortality at different reef sites varied between $50-80 \%$, and accounted for a loss of $16 \%$ of

67 healthy reefs (reviewed in Wilkinson 2000). The Northern Mozambique Channel, one of the 68 least known regions of the WIO, had variable levels of coral bleaching reported in the 1998 
69 event (Souter et al. 2000; Wilkinson 2000; Obura et al. 2018). While it is a center of diversity

70 and accumulation for coral species (Obura 2012, 2015), it may show some characteristics of

71 being a climate refuge because of its low rate of temperature rise (McClanahan et al. 2007,

72 2014). However, larger scale studies present it as among the earliest parts of the WIO to face

73 severe thermal stress conditions (Sheppard 2003, van Hooidonk et al. 2016).

74 Mayotte $\left(12.1^{\circ} \mathrm{S}, 45.1^{\circ} \mathrm{E}\right)$ is the oldest island in the Comoro archipelago, located in the center of

75 the Northern Mozambique Channel. It has somewhat lower coral diversity than surrounding

76 mainland and Madagascar coasts on account of the island area effect (Obura 2012). However,

77 it has among the highest geomorphological diversity of reef habitats in the western Indian

78 Ocean. It is highly eroded with high sedimentation and turbidity in the lagoon (Thomassin 2001).

79 Sea surface temperatures (SSTs) around Mayotte are warm and bimodal (Atewerbehan and

80 McClanahan 2010) determined by the monsoons and interactions of the South Equatorial

81 Current with Madagascar, varying between 25.5 and $29^{\circ} \mathrm{C}$. Coral bleaching on Mayotte has

82 been well documented in 1983 and 1998 (Faure et al. 1984; Quod et al. 2002), as well as in

832010 (Eriksson et al. 2012) and 2016 (Nicet et al. 2016, L Bigot and D Obura, unpublished

84 data).

85 This study is based on surveys in early June 2010 following the peak months of high sea furface

86 temperatures from February to April (fig. 1). Bleaching and mortality of corals were observed

87 throughout the island's reefs. This paper focuses on comparisons among coral genera and coral

88 colony size classes in bleaching and mortality patterns, and estimation of the full impact of the

89 bleaching event on the corals of Mayotte, in the context of repeat bleaching events.

\section{METHODS}


92 Coral reef structures on Mayotte Island are diverse, including outer reef banks and slopes, inner

93 slopes of the barrier, a second inner barrier reef at the southwest of the island and fringing reefs

94 around the main island and smaller islets (fig. 2). The island is densely populated, with high

95 pressure on the lagoon from fishing, and sedimentation from runoff and land-use change

96 (Thomassin 2001, Bigot et al. 2018).

97 Sampling for coral bleaching was conducted on the Tara Oceans Expedition from 30 May -17

98 June 2010, following peak bleaching months. Twenty seven of the 34 sites (Table 1, fig. 2) were

99 sampled between 8 and $12 \mathrm{~m}$ depth, corresponding to the zone of maximum reef development,

100 though on 2 fringing and 1 inner barrier sites the reef profile forced sampling to be done at 4-7

$101 \mathrm{~m}$, and on two outer barrier and the two bank reefs, sampling was done at 16-20 m. This paper

102 reports on two survey methods collected as part of a more comprehensive dataset (Obura and

103 Grimsditch 2009). Coral size class structure was sampled with $1 \mathrm{~m}$ wide belt transects, including

104 bleaching and mortality observations by colony, and visual estimation of abundance of coral

105 genera on a 1-5 scale, and of percent coral cover.

106 Belt transects $1 \mathrm{~m}$ wide were used for sampling coral colony sizes. Coral colonies whose center

107 fell within the belt and quadrats) were counted. The largest colony diameter was recorded, in

108 the size class bins: $11-20,21-40,41-80,81-160,161-320$ and $>320 \mathrm{~cm}$. For corals smaller

109 than $10 \mathrm{~cm}$, subsampling was done using $1 \mathrm{~m}^{2}$ quadrats at the $0,5,10,15,20$, and $25 \mathrm{~m}$

110 transect marks, in size class bins $0-2.5,3-5$ and $6-10 \mathrm{~cm}$. Colony condition was recorded as

111 unaffected (no visible effect of thermal stress), pale, bleached, partially dead or fully dead, as

112 exclusive categories by colony. Colonies were assigned to the most severe condition observed

113 if that condition occupied more than $1 / 5$ of the colony surface; ie. a colony with bleaching and

114 partial mortality was classed as partially dead if more than about $1 / 5$ was dead. A 1 m stick was

115 used to help guide estimation of transect width and mark the $1 \mathrm{~m}^{2}$ quadrats, and the stick was

116 marked at 10, 20, 40 and $80 \mathrm{~cm}$ to guide size estimation of coral colonies. A standard transect 
117 length of $25 \mathrm{~m}$ was targeted, but length was often limited by a high density of corals and time

118 available per dive. Seventeen of the 34 sites were sampled with $25-\mathrm{m}$ transects (Table 1). The

119 smallest sampling was of two $1 \mathrm{~m}^{2}$ quadrats and a 7-m belt transect, recording 18 small and 94

120 large corals, respectively. The minimum counts of 11 small and 86 large corals were recorded

121 within a 25-m transect.

122 Sampling focused on coral genera that were already known to cover a range of bleaching

123 susceptibility from high to low and that are generally common on East African reefs (Obura and

124 Grimsditch 2009): 1 - low resistance to bleaching: Acropora (including Isopora), Montipora,

125 Pocillopora, Seriatopora, Stylophora; 2 - intermediate resistance to bleaching: Echinopora,

126 Dipsastraea, Favites, Goniastrea, Leptastrea, Platygyra, Acanthastrea, Coscinaraea, Fungia,

127 Galaxea, Hydnophora, Lobophyllia, Oxypora, Pavona, Plerogyra (); 3 - high resistance to

128 bleaching: Porites (massive and branching morphologies recorded separately) and Turbinaria .

129 The relative abundance of all coral genera at a site was recorded by visual estimate, on a 5-

130 point scale (rare, uncommon, common, abundant, dominant) following Devantier and Turak

131 (2017). An index of relative abundance for each genus was calculated from these estimates as

132 the average of: the proportion of sites at which a genus was present, its average abundance

133 across all sites, and maximum abundance at any site, all converted to $0-5$ scale (Obura and

134 Grimsditch 2009).

135 For analysis of the coral size class data, all densities per genus were transformed to a standard

136 area of $100 \mathrm{~m}^{2}$. The number and area of colonies per $100 \mathrm{~m}^{2}$ was used. Colony area was

137 calculated for each size class using its median diameter and assuming the area of a coral

138 colony is approximated by an ellipse with the second diameter half of the maximum (area =

$\left.1391 / 2^{*} \mathrm{pi}^{*} \mathrm{r}^{2}\right)$. Proportions of each of the colony condition classes were calculated based on

140 abundance and area of each in each size class. For some analyses the number of classes was 
141 reduced to three, by aggregating pale and bleached (termed bleached) and partially and full

142 dead (termed dead).

143 To investigate the impact of different approaches to monitoring and reporting bleaching, two

144 variations of the bleaching and mortality data were analyzed. First, we tested the effect of

145 excluding the proportion of normal colonies, because many programmes count or report only

146 colonies showing some level of bleaching and/or mortality, and not count the number of normal

147 corals. Second, we tested the effect of weighting conditions of increasing severity, i.e. from pale,

148 to bleached, to partially dead to dead (see McClanahan et al. 2007b). We applied the following

149 weights: $1^{*}$ pale, $2^{*}$ bleaching, $3^{*}$ partial mortality and $4^{*}$ mortality. Cluster analysis using the Bray-

150 Curtis similarity index was found to give results easy to interpret for the pros and cons of the

151 different approaches. Analysis was conducted in PRIMER v6.0 with significant groupings

152 identified using SIMPROF (Clarke and Warwick 2001).

153 Estimates of the potential final mortality of corals were obtained from the size class data based

154 on the assumption that minimum mortality from the event would be equivalent to current levels

155 of partial and full mortality. This was obtained by subtracting the sum of partial and full mortality

156 from the total counts for all size classes for each genus. By contrast, the assumption that all

157 currently bleached corals would die gives an estimate of maximum mortality from the event,

158 thus subtracting the counts of bleached corals plus partial and fully dead corals. We assumed

159 that pale corals survived.

160

161 RESULTS

162 Thirty-four sites were surveyed overall, in 7 reef zones (Table 1, fig. 2). In total, 8,439 colonies

163 were sampled. Coral cover varied from a maximum of almost $80 \%$ on the offshore Banc d'Iris,

164 between $35-45 \%$ for outer barrier, inner barrier and small-island reefs within the lagoon, slightly 
165 over $30 \%$ for fringing reefs on the main island, and $<30 \%$ in the Passe en 'S', the only channel

166 site surveyed (fig. 3a). Nevertheless, coral cover was not significantly different by reef zone

167 (One Way ANOVA, $(F=1.338, P=0.275)$. No patterns were observed, nor have been reported in

168 the literature, of differential coral genus distributions around the island unrelated to reef zone, so

169 all sites were lumped together in subsequent analyses, to focus on patterns in bleaching by

170 coral traits (taxonomy, colony size). Across all sites, average coral colony abundance was 2327

$171( \pm 1253)$ and area was $41 \mathrm{~m}^{2}( \pm 21.9)$ per $100 \mathrm{~m}^{2}$ of reef. By abundance, $35 \%$ of coral colonies

172 were affected by the bleaching event, with $18.4 \%$ being pale, $9.3 \%$ bleached, $2 \%$ partially dead

173 and $5.3 \%$ dead (fig. 3b). By area, $52 \%$ of coral area or biomass was affected by bleaching, with

$17419.3 \%$ being pale, $10.7 \%$ bleached, $4.8 \%$ partially dead and $17.5 \%$ dead.

175 A total of 60 coral genera were recorded (fig. 4a), with clear dominance by Acropora, followed

176 by Porites. All of the most abundant 9 genera, and 17 of the top 25, were among those targetted

177 for size class sampling (fig. 4b). Genera omitted from size class sampling, but that were present

178 at moderate levels of abundance included Leptoseris (rank=10), Echinophyllia (11), Halomitra

179 (15), Mycedium (17), Pachyseris (18) and Podabacia (20). Acropora contributed 58\% of the total

180 area of sampled corals (fig. 4b), about 5 times greater than Porites, the second genus. Sixteen

181 genera were recorded at abundances between 1-10 $\mathrm{m}^{2}$ per $100 \mathrm{~m}^{2}$ of reef, with 4 at low

182 abundance between $0.1-1 \mathrm{~m}^{2}$, and 2 at very low abundance (Stylophora and Turbinaria). For the

183 genera sampled using both methods, the logarithm of the area sampled and their visually

184 assessed relative abundance index were strongly correlated $\left(r^{2}=0.894\right)$, though some genera

185 switched ranks between the two methods (fig. 4).

186 Bleaching and mortality varied widely across genera, from $100 \%$ bleached in Turbinaria to $6 \%$

187 pale in Acanthastrea. Genera with fewer than 20 colonies sampled (i.e. Turbinaria, Oxypora,

188 and Stylophora) are excluded from further analysis, so the following results are for the 20

189 remaining genera. The most susceptible genera to combined bleaching and mortality (fig. 5a) 
190 were Pocillopora and Montipora (>70\% total impact) followed by Lobophyllia, Porites (massive

191 species), Dipsastrea, Goniastrea, Acropora and a range of others (40-65\%). Leptastrea and

192 Acanthastrea showed lowest levels of combined pale and bleached colonies ( $\approx 6 \%)$, with no

193 mortality. Pocillopora and Acropora were the only genera with high levels of mortality (47\% and

$19432 \%$, respectively, combined partially dead and dead), though mortality was also observed in

195 Porites (massive and branching species), Echinopora, Favites, Seriatopora, Platygyra, and

196 Hydnophora. Pocillopora showed the most extensive and complex response (18\% pale, 14\%

197 bleached, $21 \%$ partially dead and $26 \%$ dead), while Acanthastrea was the least impacted (6\%

198 pale). Most genera showed a higher degree of paling (up to $50 \%$ in Dipsastraea) than full

199 bleaching (up to $31 \%$ in Montipora). Simplified into three categories (unaffected, bleached and

200 dead) and illustrated in a ternary plot, Acropora and Pocillopora showed intermediate levels of

201 all three (fig. 5b). Other genera occupy a zone near the axis marking low mortality, at varied

202 levels of unaffected and bleached.

203 Cluster analyses showed the impact of excluding unaffected colonies, and the use of weighting

204 coefficients (fig. 5c). Without weights, including 'unaffected' as a category distinguished three

205 significant clusters (case 1): a) Acropora and Pocillopora due to their high combined bleaching

206 and mortality, b) a large group of intermediate genera showing some bleaching and limited

207 mortality, and c) a smaller group of five genera mostly affected by bleaching, but at lower

208 abundance. Excluding 'unaffected' (case 2) shifted the boundary between b) and c) such that c)

209 was reduced to two genera (Leptastrea and Acanthastrea), the other three genera shifting into

210 group b). Using weighting coefficients and including 'unaffected' (case 3) altered case 1 by

211 splitting the five low-response genera into two groups - the three that were pushed into group b)

212 in one group, and Acanthastrea and Leptastrea in a separate group. Finally, using weighting

213 coefficients but excluding 'unaffected' (case 4) put all of the genera except Acanthastrea and

214 Leptastrea into a single group, and these two in their own small group. 
215 Two conclusions can be drawn from the above. First, that including normal or 'unaffected'

216 colonies in field counts and analysis is important, as cases 2 and 4 both showed less

217 discrimination of bleaching responses (less discrimination of the first order spatial patterns in fig.

218 5b) than cases 1 and 3, respectively. Second, that including weighting coefficients alters the

219 results, but varying with the set of variables included. Comparing cases 2 and 4, adding

220 weighting coefficients worsened the result, removing the distinction between Acropora and

221 Pocillopora (bleaching with mortality) from the main group of genera (paling and bleaching, no

222 mortality). Comparing cases 1 and 3, adding weighting coefficients added resolution in the low-

223 response low-abundance group, distinguishing Leptastrea and Acanthastrea (with only minor

224 paling and bleaching, < 6\%, fig. 5a) from Porites (branching), Favites and Seriatopora (from 20-

$22533 \%$ impacted, and varied amounts of paling, bleaching and mortality). While the latter result

226 adds value to interpretation, weighting should be used with caution and tested on each dataset

227 to which it is applied, to fully understand how it influences the results.

228 By area, the coral community was dominated by mature colonies in the $81-160 \mathrm{~cm}$ size class

229 (fig. 6a) followed by younger colonies from 11-80 cm and then the largest colonies above 1.6

$230 \mathrm{~m}$. Numerically, 6-10 and 11-20 cm corals were most abundant. Bleaching and mortality varied

231 by colony size (fig. 6b). Both bleaching and mortality showed a strong linear increase with coral

232 colony size, up to $1.6 \mathrm{~m}$. Of the smallest colonies only $17 \%$ were affected by bleaching, with $3 \%$

233 suffering mortality. These proportions increased progressively to the most impacted size class,

$23481-160 \mathrm{~cm}$, for which $67 \%$ of colonies were affected with $35 \%$ mortality. The sample size for

235 corals $>160 \mathrm{~cm}$ was low, with 20 and 1 in the $160-320$ and $>320 \mathrm{~cm}$ size classes, respectively,

236 compared to from 131 to 4257 colonies in the smaller size classes. For corals $<10 \mathrm{~cm}$, the ratio

237 of mortality to bleaching was $<0.2$, which increased to $0.3-0.5$ for intermediate colonies from

$23810-80 \mathrm{~cm}$. For larger corals, $81-160$ and $161-320 \mathrm{~cm}$, mortality exceeded bleaching, with ratios

239 of 1.6 and 1.1 respectively. 


\section{DISCUSSION}

242 Bleaching and mortality averaged 30 and $22 \%$, respectively, across all sites (fig. $3 \mathrm{~b}$ ) though with

243 high levels of variability from near zero at sites in the south to maximum mortality levels at sites

244 in the north and east of Mayotte. These results agree largely with Eriksson et al. (2012) who

245 found $10 \%$ bleached and $40 \%$ dead corals on the more highly impacted northern and eastern

246 reefs during May 2010. Percent coral cover varied over a wide range across reef zones in

247 Mayotte (fig. 3a) though without statistical significance. Accordingly, we aggregate the coral

248 community of Mayotte to analyze variance in bleaching response among genera.

250 Do genus and size affect coral bleaching?

251 Pocillopora and Acropora were the only coral genera to show significant mortality as a result of

252 the 2010 event, setting them apart from the others as the most susceptible genera to bleaching,

253 in accordance with findings throughout the Indo-Pacific (Marshall and Baird 2000; Obura 2001;

254 Loya et al. 2001; McClanahan et al. 2004; van Woesik et al. 2011). Cluster analysis of the

255 bleaching responses identified two additional groups of species - a large group with

256 intermediate responses characterized by variable but low mortality and variable levels of pale

257 and bleached colonies (group 'b', case 1, fig. 5c), and a smaller group with low levels of

258 bleaching and variable but low mortality (group 'c'). The middle group included a wide range of

259 genera including Porites (massive species), various merulinids, agariciids, siderastreids, and

260 fungiids. The last group included Porites (branching species), Favites, Seriatopora,

261 Acanthastrea, and Leptastrea. These groups are in broad agreement with previous reports from

262 East Africa (e.g. massive Porites is usually ranked among the least susceptible to bleaching and

263 mortality, branching Porites among the most susceptible - Obura 2001, McClanahan 2004). We 
264 have not analyzed the symbiont characteristics of genera sampled here, which has significant

265 effects on bleaching susceptibility and mortality, particularly when different host-symbiont

266 combinations may be possible (e.g. see Stat et al. 2005; Baker and Romanski 2007; Oliver and

267 Palumbi 2009). Overall, though this appeared to be a severe bleaching event for reefs in

268 Mayotte due to the dominance of Acropora and consequent loss of total coral cover, and visual

269 dominance of bleached and dead Acropora and Pocillopora, the thermal stress to other genera

270 was not sufficient to result in significant mortality.

271 A clear size differential in bleaching and mortality susceptibility was found, with susceptibility

272 being greatest in large corals. For corals in the three smallest size classes (fig. 6b) the

273 proportion of bleached colonies increased (15 to $25 \%$ ) with size, with little increase in the

274 proportion of mortality ( $<5 \%)$. For adult corals from $10 \mathrm{~cm}$ and above, the proportion of bleached

275 corals remained relatively stable (25\%), but the proportion of mortality increased (10 to $40 \%$ ),

276 and exceeded the proportion bleached. This response was strongly determined by the size-

277 dependent response of Acropora, but it did occur in other genera (fig. 7h). Lower bleaching

278 levels in small colonies, and particularly recruits, has been noted in other locations and coral

279 taxa, particularly Oculina patagonica in the Mediterranean (Shenkar et al. 2005), and three

280 dominant species in the Florida Keys (Colpophyllia natans, Montastrea faveolata, and

281 Siderastrea siderea, Brandt 2009). However, in a mild bleaching event Ortiz et al. (2010) found

282 no relation of size to bleaching extent, and Bak and Meesters (1999) predicted that bleaching

283 impacts would be selectively higher on small rather than large corals.

284 From a methodological point of view, these results suggest several important considerations for 285 measuring the impact of bleaching events at colony level, and extrapolating to community level 286 indices. First, colony size is important in the bleaching susceptibility of corals for two reasons -

287 smaller corals are less susceptible to bleaching, and larger corals have an exponentially greater 288 contribution to biomass and area. Second, it is important to include unaffected colonies in the 
counts, as this improves identification of differential bleaching responses (fig. 5c), and without total numbers of colonies the prevalence of bleaching and mortality in relation to the total

291 population cannot be determined. Third, a corollary of the first two, is the importance of an

292 unbiased sample of all corals, unaffected and bleached, and across all size classes. Without a

293 strict fixed-area sampling method, such as with a physical transect or quadrat as a guide,

294 unconstrained or haphazard counts are likely to both a) oversample colonies that show a

295 response over unaffected ones, as observers will tend to count what they are looking for

296 (bleached and dead corals) and many normal colonies are brown and inconspicuous, and b)

297 small colonies will always be under-sampled compared to larger colonies, particularly when

298 including sizes under $10 \mathrm{~cm}$. Fourth, differential weighting of bleaching and mortality categories

299 can have a strong influence on results, so should be done with caution in each case. In our

300 results it improved discrimination of low-response groups when all colonies (impacted and

301 unaffected) were included, but when unaffected corals were excluded it worsened the result.

302 Thus where sampling is not restricted by physical quadrats or transects, and the size of corals is

303 not measured (one and three above), the impact of weighting on results may not be possible to 304 ascertain.

\section{Estimating the impact of a bleaching event}

306 The surveys took place in early June, over 1 month after the end of peak temperatures at the 307 end of April 2010 (fig. 1), so this dataset likely presents peak levels of combined bleaching and 308 mortality. This is a common challenge in interpreting the eventual impact of a bleaching event, 309 as surveys are often targeted for peak bleaching conditions, but unless follow up surveys are 310 done, it cannot be known if bleached corals recovered or died. However, the envelope of

311 possible outcomes of a bleaching event can be estimated from peak bleaching levels assuming

312 further mortality from bleaching is either zero or maximal. That is, currently bleached corals all

313 recover, or die, respectively. 
314 The present dataset allows this to be done across coral size classes and genera, to estimate

315 minimum and maximum potential impact of the bleaching event (fig. 7). By number of colonies

316 the minimum and maximum loss of corals appears minor (fig. 7a) but is significant by area (fig.

317 7b), particularly for $81-160 \mathrm{~cm}$ corals. Maximum mortality by colony abundance is estimated at

318 10-15\% for Acropora, Porites (massive) and other genera (fig. 7c), but at 50\% for Pocillopora.

319 By contrast, maximum mortality by colony area is estimated at $40 \%$ for Acropora, $25 \%$ for

320 Porites (massive), $<20 \%$ for other genera (fig. 7 c), but at $>60 \%$ for Pocillopora. By colony

321 abundance, maximum mortality overall is estimated at $16 \%$, but by colony area, $32 \%$, a major

322 difference in result affected by consideration of colony area. This is because the bleaching

323 event preferentially impacted larger colonies, paticularly Acropora, eliminating the dominance of

324 81-160 m colonies (fig 7d). Reefs in Mayotte are strongly dominated by staghorn and tabular

325 Acropora species, and dominance of the $81-160 \mathrm{~cm}$ size class in April suggests the community

326 was approaching maturity where the community would be dominated by even larger stands of

327 tabular and staghorn Acropora. The bleaching event strongly flattened the size class distribution

328 with similar area in $41-320 \mathrm{~cm}$ classes after the event.

329 Pocillopora populations were strongly dominated by $21-40 \mathrm{~cm}$ and $11-20 \mathrm{~cm}$ colonies pre-

330 bleaching (fig. 7e), providing the corresponding peak in the overall population curve (figs. 5a,

$3316 b$ ); their area was reduced by about $60 \%$ by the bleaching event (fig. 7c), though they still

332 remained dominant over other size classes of Pocillopora. The population of massive Porites

333 was strongly dominated by $81-160 \mathrm{~cm}$ corals, which remained dominant after bleaching. The

334 remaining genera were most strongly represented by $11-40 \mathrm{~cm}$ colonies, and mortality was

335 relatively minor and evenly spread across them, maintaining the same size class distribution

336 following bleaching. Finally, estimated maximum mortality increased with size for all corals and

337 for the three key genera Acropora, Pocillopora, and Porites (fig. 7h). Interestingly, these three

338 genera all show a decline in mortality for their largest size class. 


\section{Recurring bleaching in Mayotte}

340 The coral reefs of Mayotte have been impacted by multiple significant bleaching events. In

341 May-June 1983 bleaching was documented at 0-18\% for fringing reefs, $30-45 \%$ for lagoon

342 reefs and $30-75 \%$ for outer barrier reefs, though an indication of the final mortality was not

343 noted (Faure et al. 1984). In 1998, 36\% of the reefs had not recovered from the 1983 bleaching

344 event, and mortality of $>80 \%$ of Acropora tables on outer reef slopes was reported from April to

345 August (Quod et al. 2002), which judging by patterns in this study may have reflected

346 approximately 50\% mortality including inner reefs. The 2010 event recorded here resulted in

$34732 \%$ mortality of all corals, and just under $40 \%$ for Acropora alone (fig. 7c). Observations in

3482016 suggest that mortality of corals was between 25 and $50 \%$ using the same methods used

349 here (by area, DO pers. obs.), and was recorded at $10-30 \%$ by colony number using other

350 methods (Nicet et al. 2016), so roughly comparable to the 2010 event.

351 In all four events, higher impact occurred on outer barrier reefs and lower levels in the lagoon

352 and on fringing reefs, and the most dramatic bleaching and mortality was of tabular and

353 staghorn Acropora colonies on outer reefs. Because of its dominance of the coral community,

354 Acropora's response to thermal stress dominated the overall community response. The intervals

355 between these major bleaching events has progressively declined - from 16 years to ten and six

356 years. Across all of these events the reefs have apparently achieved considerable recovery and

357 maintained the same dominance by Acropora. This suggests a high degree of community

358 resilience, likely partly a result of high levels of connectivity (Crochelet et al. 2015) due to the

359 complex eddies that maintain high self-seeding of reefs within the northern Mozambique

360 channel (Obura et al., 2018; Bigot et al. 2018).

361 However, anthropogenic stresses in Mayotte from both fisheries and water quality degradation

362 (Wickel and Thomassin 2005) are increasingly evident in the greater prevalence of coral

363 disease and chronic mortality from unknown sources (DO pers. obs., 2016). This will likely 
364 undermine the natural resilience of the reefs (Obura 2005; Hughes et al. 2010) and may reduce

365 their ability to recover from the 2016 bleaching event.

366 Between latitude S 12-13.5 and longitudes E 44.5-45.5 (a box around Mayotte) SST has

367 warmed by $0.096^{\circ} \mathrm{C}$ per decade for the thirty-year period from 1981-2010 (Reynolds et al.

368 2005), slightly less than the global level of $0.147^{\circ} \mathrm{C}$ per decade (Rayner et al. 2003). Mayotte is

369 in the region with the lowest SST rise in Eastern Africa (McClanahan et al. 2007a). Donner

370 (2009) estimated a rate of SST rise to which corals must adapt to avoid catastrophic coral

371 decline, of $1.5^{\circ} \mathrm{C}$ in $50-80$ years. This is $0.2-0.3^{\circ} \mathrm{C}$ per decade, some $2-3$ times higher than the

372 rise in temperatures that coral reefs in Mayotte have experienced over the course of four

373 bleaching events. While Mayotte's reefs have shown remarkable resilience so far, it is not clear

374 that they are acclimating or adapting sufficiently to the rise experienced of $0.1^{\circ} \mathrm{C}$ per decade.

375 Further, the shorter intervals for recovery between events, matching the global pattern now at

376 sub-decadal levels (Hughes et al. 2018), is approaching limits for recovery consistently used in

377 framing the onset of 'catastrophic' bleaching (Sheppard 2003, van Hooidonk et al. 2016).

378 CONCLUSION

379 The most recent analysis identifies 2030 as approximately the year in which Mayotte will

380 experience Annual Severe Bleaching under RCP 8.5 (business as usual scenario, equivalent to

381 today's CO2 emission rates; van Hooidonk et al. 2016). That the reefs are already experiencing

382 decadal severe bleaching only $15-20$ years earlier is strong indication that the trajectory for coral

383 reefs in the region towards decline may be inexorable on the time scales at hand, and that the

384 reefs cannot withstand annual occurrence of the scale of bleaching documented in 1983, 1998

385 and 2010, and repeated in 2016 (Nicet et al. 2016). Although the Northern Mozambique

386 Channel may be a center of diversity and of key significance to the Western Indian Ocean at

387 large (Obura 2012, Obura et al. 2018), it may not be a refuge from warming for coral reefs

388 (McClanahan et al. 2014) and urgent and emergency planning is needed to identify what can be 
389 done to secure the best possible future not just for the reefs of Mayotte or the WIO, but also

390 more broadly on a global scale (Beyer et al., 2018).

391

\section{ACKNOWLEDGEMENTS}

393 We are grateful to Etienne Bourgois, the Tara schooner and its captain Hervé Bourmand,

394 Mathieu Oriot (Diving Officer) the Tara crew, the Oceans Consortium, and James Mbugua.

\section{REFERENCES}

397

398

Ateweberhan M, McClanahan TR (2010) Relationship between historical sea-surface temperature variability and climate change-induced coral mortality in the western Indian Ocean. Mar Poll Bull 60:964-970

Bak RPM, Meesters E (1999) Population structure as a response of coral communities to global change. Amer Zool 39:56-67

Baker AC, Romanski AM (2007) Multiple symbiotic partnerships are common in scleractinian corals, but not in octocorals: Comment on Goulet (2006). Mar Ecol Progr Ser 335:237-242

Beyer HL, Kennedy EV, Beger M, Chen CA, Cinner J, Darling E, Eakin CM, Gates R, Heron SF, Knowlton N, Obura DO, Palumbi SR, Possingham HP, Puotinen M, Runting RK, Skirving W, Spalding M, Wilson K, Wood S, Veron JE, Hoegh-Guldberg O (2018). Long-term risksensitive planning for conserving coral reefs under rapid climate change. Conservation Letters (in press).

Bigot L, Chabanet P, Cuet P, Cauvin B, Durville P, Mulochau T, Nicet JB, Tessier E, Thomassin B, Wickel J, Naim O (2018) The French territories in the South Western Indian Ocean. In: World Seas: an Environmental Valuation, Volume II: The Indian Ocean to the Pacific, Second Edition. Editor: Charles Sheppard. Elsevier. 
413 Brandt ME (2009) The effect of species and colony size on the bleaching response of reef-

414 building corals in the Florida Keys during the 2005 mass bleaching event. 28:911-924

415 Chin A, Lison De Loma T, Reytar K, Planes S, Gerhardt K, Clua E, Burke L, Wilkinson C.

416 (2011). Status of Coral Reefs of the Pacific and Outlook: 2011. Publishers Global Coral

417 Reef Monitoring Network. 260 pp.

418 Clarke KR, Warwick RM (2001) Change in Marine Communities: An Approach to Statistical

419 Analysis and Interpretation, 2nd edn. PRIMER-E, Plymouth

420 Crochelet E., Roberts J., Lagabrielle E., Obura D.O., Petit M., \& Chabanet P. (2016) A model-

421 based assessment of reef larvae dispersal in the Western Indian Ocean reveals regional

422 connectivity patterns - Potential implications for conservation policies. Regional Studies in

$423 \quad$ Marine Science, 7, 159-167.

424 Devantier L. \& Turak E. (2017) Species Richness and Relative Abundance of Reef-Building

425 Corals in the Indo-West Pacific. Diversity, 9, 25.

426 Donner SD (2009) Coping with commitment: projected thermal stress on coral reefs under

427 different future scenarios. PLoS ONE 4:e5712. doi:10.1371/journal.pone.0005712

428 Donner SD, Rickbeil GJM, Heron SF (2017) A new, high-resolution global mass coral bleaching

429 database. PLoS ONE 12(4): e0175490. https://doi.org/10.1371/journal.pone.0175490

430 Eakin C.M., Morgan J.A., Heron S.F., Smith T.B., Liu G., Alvarez-Filip L., Baca B., Bartels E.,

431 Bastidas C., Bouchon C., Brandt M., Bruckner A.W., Bunkley-Williams L., Cameron A.,

432 Causey B.D., Chiappone M., Christensen T.R.L., Crabbe M.J.C., Day O., la Guardia de E.,

433 Diaz-Pulido G., DiResta D., Gil-Agudelo D.L., Gilliam D.S., Ginsburg R.N., Gore S.,

434 Guzmán H.M., Hendee J.C., Hernández-Delgado E.A., Husain E., Jeffrey C.F.G., Jones

435 R.J., Jordán-Dahlgren E., Kaufman L.S., Kline D.I., Kramer P.A., Lang J.C., Lirman D.,

436 Mallela J., Manfrino C., Maréchal J.-P., Marks K., Mihaly J., Miller W.J., Mueller E.M.,

437 Muller E.M., Orozco Toro C.A., Oxenford H.A., Ponce-Taylor D., Quinn N., Ritchie K.B.,

438 Rodríguez S., Ramírez A.R., Romano S., Samhouri J.F., Sanchez J.A., Schmahl G.P., 
Shank B.V., Skirving W.J., Steiner S.C.C., Villamizar E., Walsh S.M., Walter C., Weil E., Williams E.H., Roberson K.W., \& Yusuf Y. (2010) Caribbean corals in crisis: record thermal stress, bleaching, and mortality in 2005. PLoS ONE, 5, e13969.

Eriksson H., Wickel J., \& Jamon A. (2012) Coral bleaching and associated mortality in Mayotte, Western Indian Ocean. Western Indian Ocean Journal of Marine Science, 11, 113-118.

Faure G, Guillaume M, Payri C, Thomassin BA, Van Praet M, Vasseur P (1984) Sur un phénomène remarquable de blanchiment et de mortalité massive des madréporaires dans le complexe récifal de l'île Mayotte (SW Ocean Indien). C.R. Acad. Sc. Paris, 299-III$15: 637-642$

Goreau T, McClanahan TR, Hayes R, Strong A (2000). Conservation of coral reefs after the 1998 global bleaching event. Cons. Biol. 14:5-15

Hoegh-Guldberg O, Mumby PJ, Hooten AJ, Steneck RS, Greenfield P, Gomez E, Harvell CD, Sale PF, Edwards AJ, Caldeira K, Knowlton N, Eakin CM, Iglesias-Prieto R, Muthiga N, Bradbury RH, Dubi A, Hatziolos ME (2007) Coral reefs under rapid climate change and ocean acidification. Science 318:1737-1742 M. (2017a) Coral reefs in the Anthropocene. Nature, 546, 82-90.

Hughes T.P., Kerry J.T. and ... Wilson S.K. (2017b) Global warming and recurrent mass bleaching of corals. Nature 543, 373-377.

Hughes T.P., Anderson K.D., Connolly S.R., Heron S.F., Kerry J.T., Lough J.M., Baird A.H., 460 Baum J.K., Berumen M.L., Bridge T.C., Claar D.C., Eakin C.M., Gilmour J.P., Graham N.A.J., Harrison H., Hobbs J.-P.A., Hoey A.S., Hoogenboom M., Lowe R.J., McCulloch M.T., Pandolfi J.M., Pratchett M., Schoepf V., Torda G., \& Wilson S.K. (2018) Spatial and temporal patterns of mass bleaching of corals in the Anthropocene. Science, 359, 80-83. 
464 Hughes TP, Graham NAJ, Jackson JBC, Mumby PJ, Steneck RS (2010) Rising to the challenge 465 of sustaining coral reef resilience. Trends Ecol. \& Evol. 25:633-642.

$466 \quad$ doi:10.1016/j.tree.2010.07.011

467 Jackson JBC et coll., 2014. Part I: overview and synthesis for the wider Caribbean, in: Status

468 and trends of Caribbean Coral Reefs : 1970-2012. Jackson Jbc, Donovan Mk, Cramer Kl, 469 Lam V (eds). IUCN publications : 55-113

470 Loya Y, Sakai K, Yamasato K, Nakano Y, Sambali H, van Woesik R (2001) Coral bleaching: the $471 \quad$ winners and the losers. Ecol Lett 4:122-131

472 Marshall PA, Baird AH (2000) Bleaching of corals on the Great Barrier Reef: differential $473 \quad$ susceptibilities among taxa. Coral Reefs 19:155-163

474 McClanahan TR (2004). The relationship between bleaching and mortality of common corals.

475 Marine Biology, 144(6), 1239-1245. http://doi.org/10.1007/s00227-003-1271-9

476 McClanahan TR, Ateweberhan M, Darling ES, Graham NAJ, \& Muthiga NA (2014)

477 Biogeography and Change among Regional Coral Communities across the Western Indian $478 \quad$ Ocean. PLoS ONE, 9, e93385.

479 McClanahan TR, Ateweberhan M, Muhando C, Maina J, Mohammed SM (2007a) Effects of $480 \quad$ climate and seawater temperature variation on coral bleaching and mortality. Ecol. Monogr. $481 \quad 77: 503-525$

482 McClanahan TR, Ateweberhan M, Ruiz Sebastian C, Graham NAJ, Wilson SK, Bruggemann $483 \mathrm{JH}$, Guillaume MMM (2007b) Predictability of coral bleaching from synoptic satellite and in 484 situ temperature observations. Coral Reefs 26:695-791.

485 McClanahan TR, Baird AH, Marshall PA, Toscano MA (2004) Comparing bleaching and 486 mortality responses of hard corals between southern Kenya and the Great Barrier Reef, 487 Australia. Mar Pollut Bull 48:327-335 
488 McClanahan TR, Maina J, Moothien-Pillay R, Baker AC (2005) Effects of geography, taxa,

489 water flow, and temperature variation on coral bleaching intensity in Mauritius. Mar. Ecol.

$490 \quad$ Prog. Ser. 298:131-142

491 McPhaden MJ, Zebiak SE, Glantz MH (2004) ENSO as an Integrating Concept in Earth Science $492 \quad$ Science $314: 1740-5$

493 Nicet JB, Pennober G, Buckleen M, Wickel J, Bigot L, Chabanet P, Obura D) (2016) Intensité et 494 impact du blanchissement corallien massif de 2016 sur les récifs coralliens français de 495 I'océan Indien. Projet BECOMING 2016. Rapport MAREX, ESPACEDEV, ENTROPIE, UR, 496 IRD, SEAS-OI, CORDIO, AAMP, PNMM, PNMG, TAAF, RNMR, DEAL Réunion, RNB, $497 \quad$ IFRECOR, UE, 87 pages.

498 Obura DO (2001) Can differential bleaching and mortality among coral species offer useful 499 indicators for assessment and management of reefs under stress? Bull. Mar. Sci. 69:421$500 \quad 442$

501 Obura DO (2005) Resilience and climate change: lessons from coral reefs and bleaching in the 502 western Indian Ocean. Estuar. Coast. Shelf Sci. 63:353-372

Obura DO (2012) The diversity and biogeography of Western Indian Ocean reef-building corals.

$504 \quad$ PLOS ONE. http://dx.plos.org/10.1371/journal.pone.0045013.

505 Obura DO (2016), An Indian Ocean centre of origin revisited: Palaeogene and Neogene 506 influences defining a biogeographic realm. Journal of Biogeography. 43:229-242 doi: $507 \quad$ 10.1111/jbi. 12656.

508 Obura DO, Bandeira SO, Bodin N, Burgener V, Braulik G, Chassot E, Gullström M, Kochzius M, 509 Nicoll M, Osuka K, Ralison HO, Richmond M, Samoilys MA, Scheren P, Ternon J-F (2018) 510 The Northern Mozambique Channel. In: World Seas: an Environmental Valuation, Volume 511 II: The Indian Ocean to the Pacific, Second Edition. Editor: Charles Sheppard. Elsevier. 
512 Obura DO, Grimsdith G (2009). Resilience Assessment of coral reefs - Assessment protocol for

513 coral reefs, focusing on coral bleaching and thermal stress. IUCN working group on Climate

514 Change and Coral Reefs. IUCN, Gland, Switzerland. ISBN: 978-2-8317-1151-5

515 Obura DO, Gudka M, Abdou Rabi F, Bacha Gian S, Bigot L, Bijoux J, Freed S, Maharavo J,

516 Munbodhe V, Mwaura J, Porter S, Sola E, Wickel J, Yahya S and Ahamada S (2017) Coral

517 reef status report for the Western Indian Ocean. Global Coral Reef Monitoring Network

518 (GCRMN)/International Coral Reef Initiative (ICRI). pp 144.

519 Oliver T, Palumbi S (2009) Distributions of stress-resistant coral symbionts match environmental

520 patterns at local but not regional scales. Mar. Ecol. Prog. Ser. 378:93-103.

521 Ortiz JC, del C. Gomez-Cabrera M, Hoegh-Guldberg O (2009) Effect of colony size and

522 surrounding substrate on corals experiencing a mild bleaching event on Heron Island reef

523 flat (southern Great Barrier Reef, Australia). Coral Reefs 28:999-1003

524 Quod J, Dahalani Y, Bigot L, Nicet J-B, Ahamada S, Maharavo J (2002) Status of Coral Reefs

525 at Réunion, Mayotte and Madagascar. In: Linden O, Souter D, Wilhelmsson D, Obura D

526 (Eds) Coral Reef Degradation In The India Ocean. Status reports 2002. CORDIO/SAREC

527 Marine Science Program. pp. 185-189

528 Rayner NA, Parker DE, Horton EB, Folland CK, Alexander LV, Rowell DP, Kent EC, Kaplan A

529 (2003) Global analyses of sea surface temperature sea ice and night marine air

530 temperature since the late nineteenth century J. Geophys. Res.Vol. 108: D14 4407

$531 \quad 10.1029 / 2002 J D 002670$

532 Reynolds RW, Rayner NA, Smith TM, Stokes DC, Wang W (2002) An improved in situ and

533 satellite SST analysis for climate. J. Climate 15: 1609-1625

534 Saji N.H., Goswami B.N., Vinayachandran P.N., \& Yamagata T. (1999) A dipole mode in the

535 tropical Indian Ocean. Nature, 401, 360-363.

536 Shenkar N, Fine M, Loya Y (2005) Size matters: bleaching dynamics of the coral Oculina

537 patagonica. Mar Ecol Prog Ser 294:181-188 
538 Sheppard C.R. (2003) Predicted recurrences of mass coral mortality in the Indian Ocean.

$539 \quad$ Nature, 425, 294-297.

540 Souter D. Obura DO, Linden O (2000) Coral Reef Degradation In The India Ocean. Status

541 reports 2000. CORDIO/SAREC Marine Science Program. ISBN 91-973959-1-9

542 Stat M, Loh WKW, LaJeunesse TC, Hoegh-Guldberg O, Car DA (2009) Stability of coral-

543 endosymbiont associations during and after a thermal stress event in the southern Great

$544 \quad$ Barrier Reef Coral Reefs 28:709-13

545 Thomassin BA (2001) Mayotte (SW Indian Ocean): Recent demographical and economical rise

546 induced by anthropisation and/or climatic variations on the littoral and on lagoonal

547 ecosystems. J. Rech. Oceanogr. 26:60

548 van Hooidonk R., Maynard J., Tamelander J., Gove J., Ahmadia G., Raymundo L., Williams G.,

549 Heron S.F., \& Planes S. (2016) Local-scale projections of coralreef futures and implications

$550 \quad$ ofthe Paris Agreement. Scientific Reports, 1-8.

551 van Woesik R, Sakai K, Ganase A, Loya Y (2012) Revisiting the winners and the losers a

552 decade after coral bleaching. Mar. Ecol. Progr. Ser. 434: 67-76

553 UNEP-WCMC, WorldFish Centre, WRI, TNC (2010). Global distribution of warm-water coral

554 reefs, compiled from multiple sources including the Millennium Coral Reef Mapping Project.

555 Version 3.0. Includes contributions from IMaRS-USF and IRD (2005), IMaRS-USF (2005)

556 and Spalding et al. (2001). Cambridge (UK): UN Environment World Conservation

557 Monitoring Centre. URL: http://data.unep-wcmc.org/datasets/1

558 Wickel J, Thomassin BA (2005) Les récifs coralliens frangeants de l'île de Mayotte (Grande

559 Terre): bilan de l'état de santé en 2004 et évolution depuis 1989. daf976.agriculture.gouv.fr

560 Wilkinson C (2000) Status of Coral Reefs of the World: 2000. Australian Institute of Marine

$561 \quad$ Science, Townsville, Australia 
562 Wilkinson C, Linden O, Cesar H, Hodgson G, Rubens J, Strong A (1999) Ecological and

563 socioeconomic impacts of 1998 coral mortality in the Indian Ocean: An ENSO impact and a 564 warning of future change? Ambio 28:188-196. 
Figure 1

Sea Surface Temperature (SST) in the Western Indian Ocean, by month, from January to July 2010.

Mean monthly level 3 data at $4 \mathrm{~km}$ resolution, source: Moderate Resolution Imaging Spectroradiometer (MODIS), https://oceancolor.gsfc.nasa.gov/cgi//3.

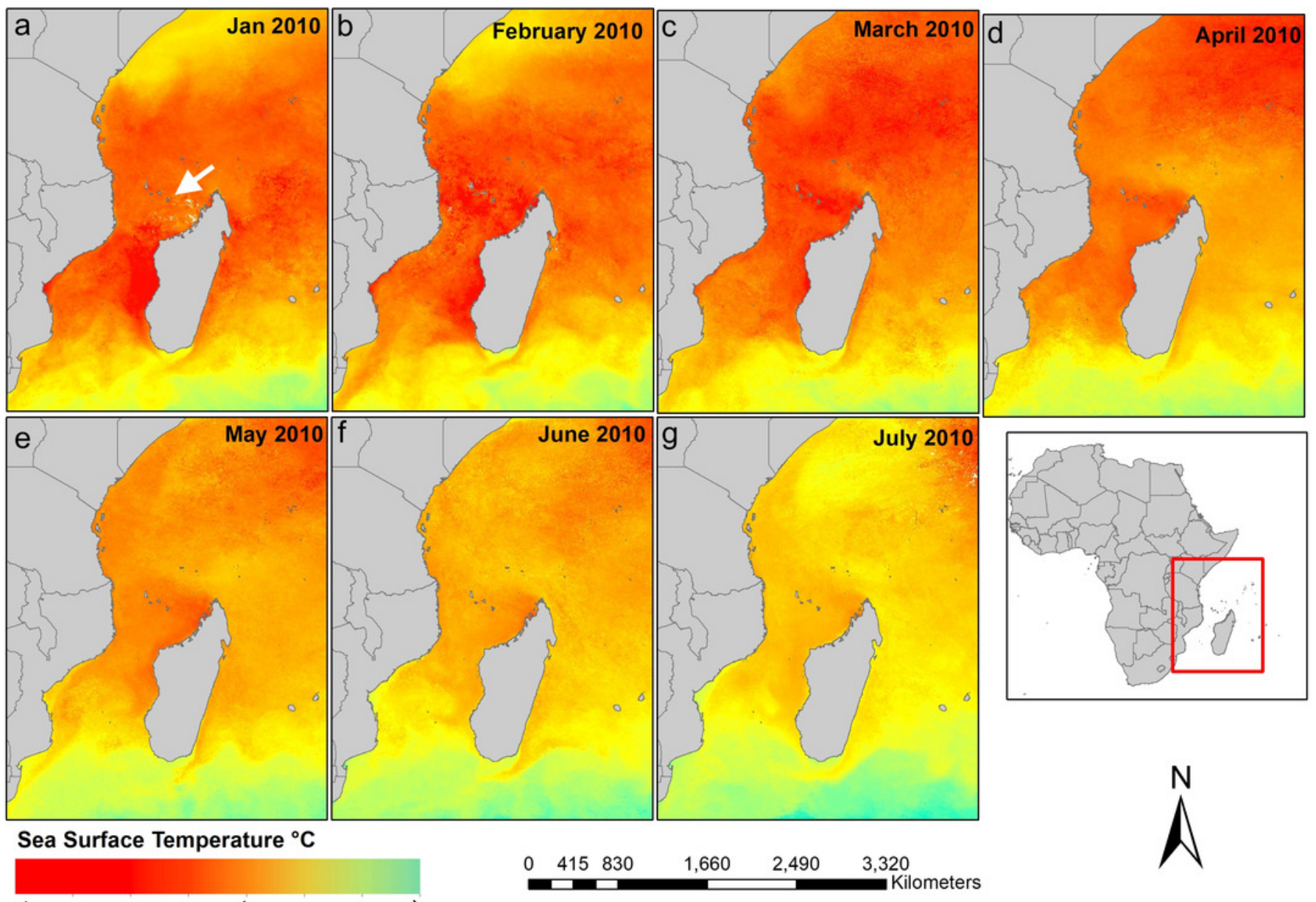


Figure 2

Map of Mayotte, showing the reef and lagoon structure, and sampling sites coded by reef zone.

WCMC et al. (2010) 

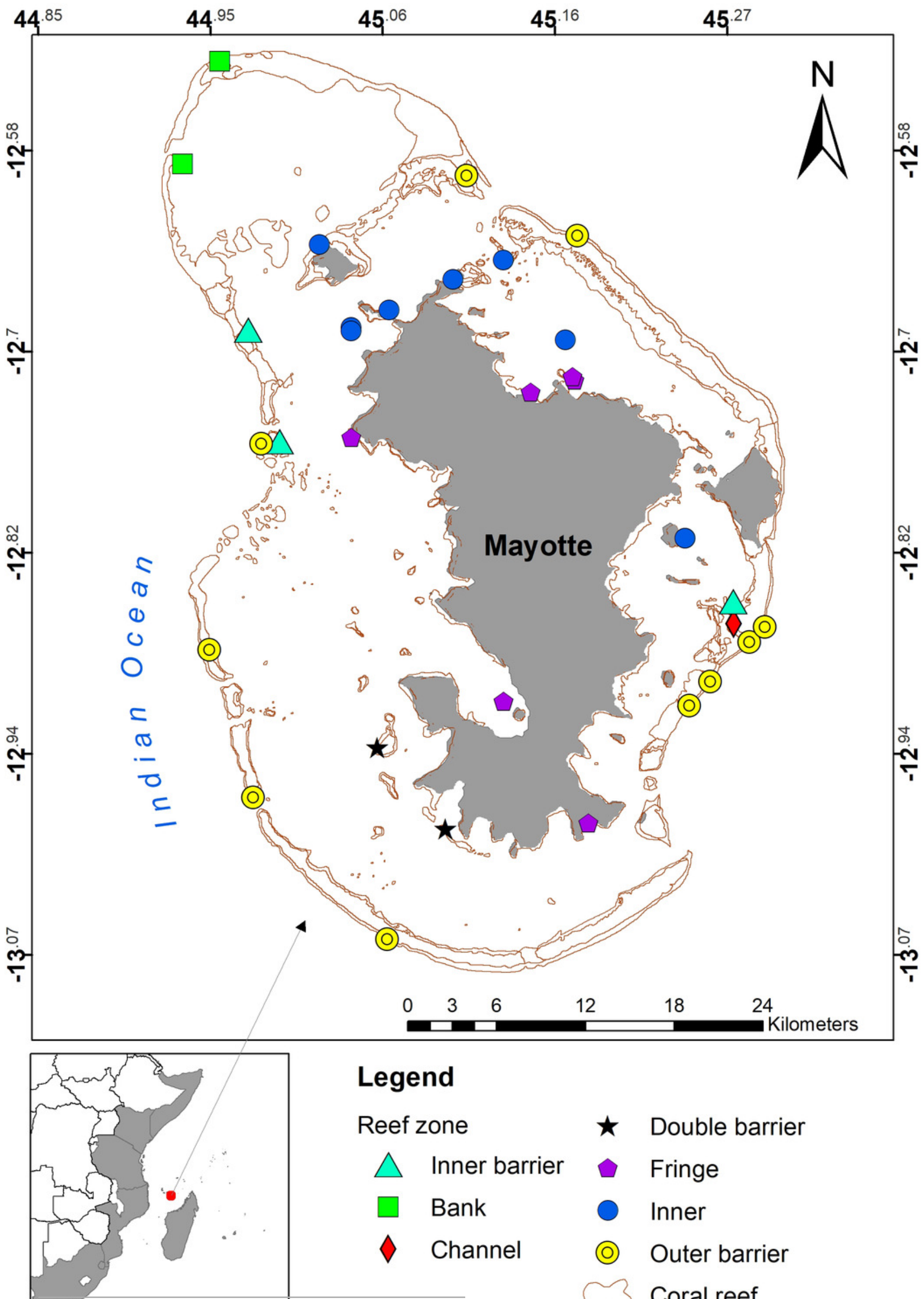

\section{Legend}

Reef zone

$\triangle$ Inner barrier

- Bank

$\diamond$ Channel $\star \quad$ Double barrier

Fringe

- Inner

(0) Outer barrier 


\section{Figure 3}

Coral cover and condition in Mayotte, June 2010.

a) Coral cover by reef zone (mean \pm se). The number of sites sampled in each zone is shown in parentheses in the $\mathrm{x}$ axis labels. b) Proportional bleaching and mortality of corals in Mayotte, in June 2010, by number and area of colonies sampled.

a

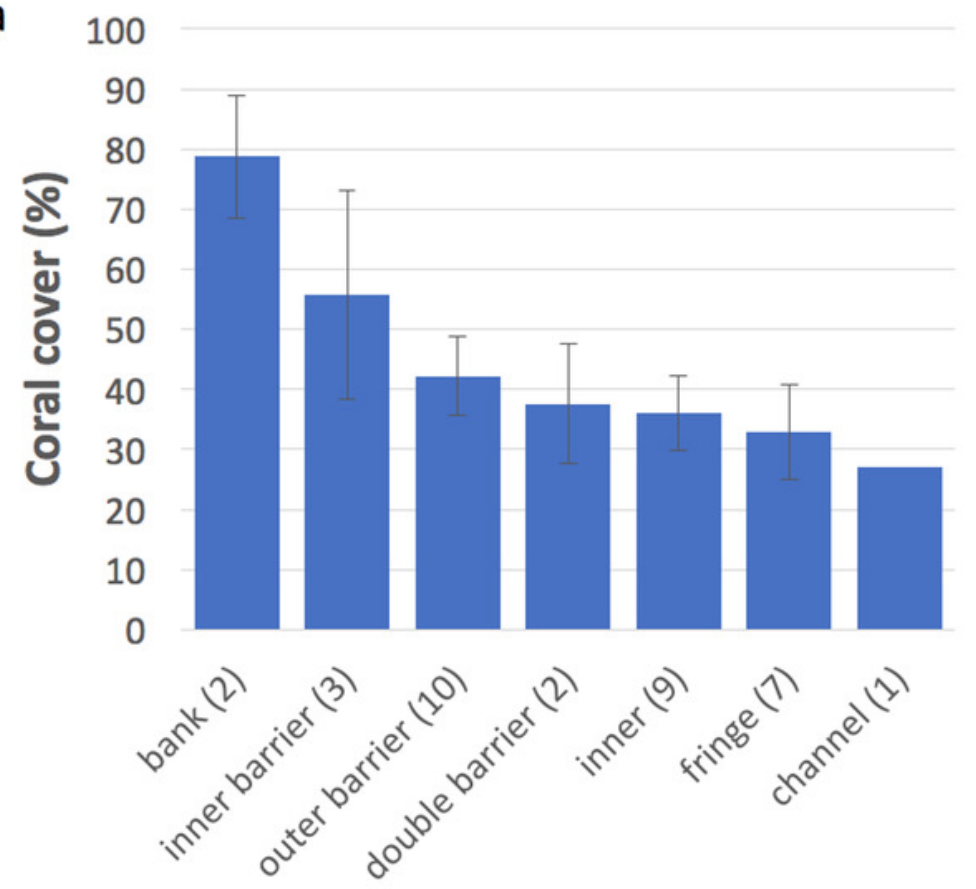

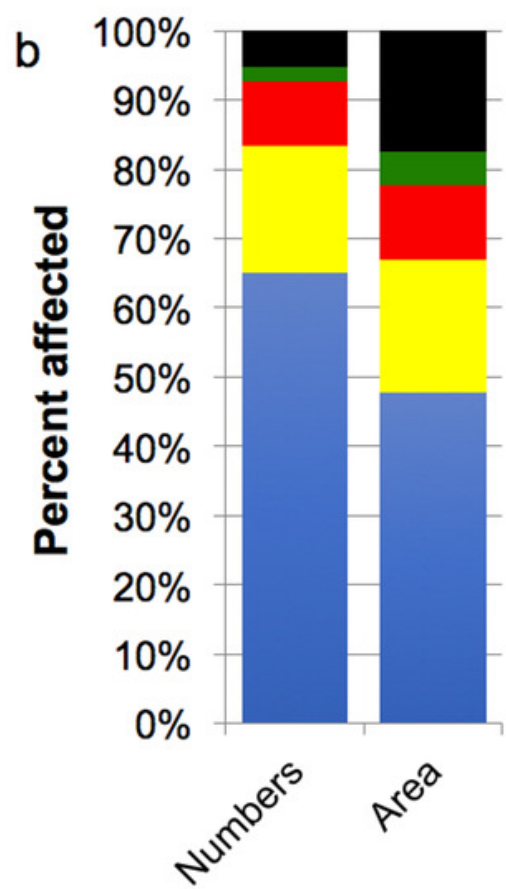

dead

mart dead

- bleached

pale

normal 


\section{Figure 4}

Coral genera sampled, Mayotte, 2010.

a) relative abundance of all coral genera identified, aggregated across sites. The index of relative abundance ranges from a maximum of 5 , with zero representing absence. Site level scores were: rare (1), uncommon (2), common (3), abundant (4) and dominant (5). b) Area (biomass) of each genus measured in size class transects (in $\mathrm{m}^{2}$ per $100 \mathrm{~m}^{2}$ of reef area), ranked from highest to lowest. Genera sampled in both methods ( $a$ and b) shaded red, genera sampled only in visual estimates (in a) shaded blue.
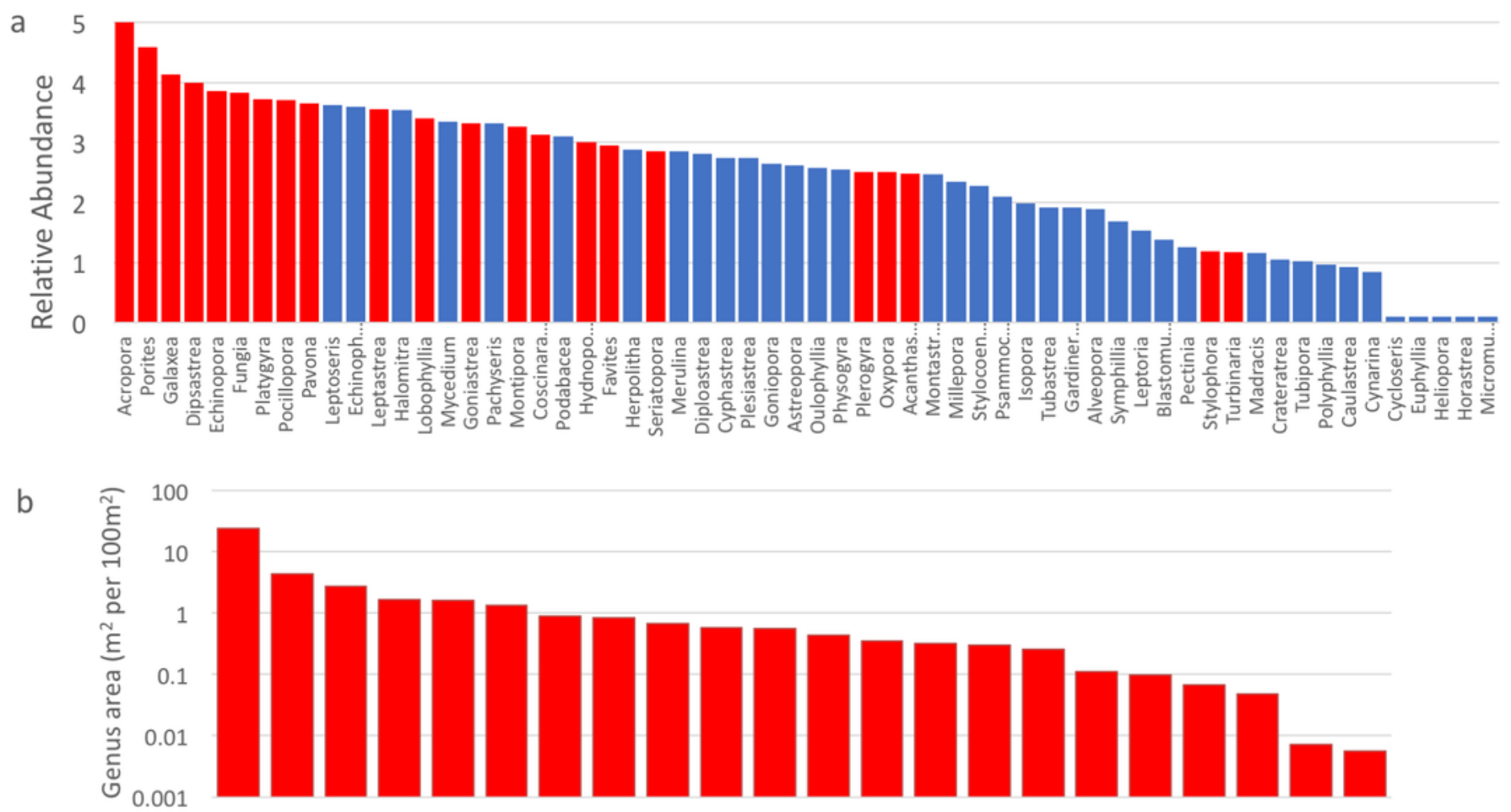


\section{Figure 5}

Bleaching and mortality of coral genera.

a) proportion of bleaching and mortality by genus, excluding the two least abundant genera.

b) Ternary plot of unaffected, bleached (pale plus bleached) and dead (partial plus full mortality) for genera sampled in the study. Key genera are indicated using three-letter codes that correspond to the first three letters of genus names in (a) and (c), except for 'fat' (Favites), 'mtp' (Montipora), 'porb' (branching Porites) and 'porm' (massive Porites). c) Cluster analysis results with SIMPROF test to show significant clusters of genera at $p=5 \%$ level for four cases: unweighted proportions of pale, bleached, partial and full mortality analyzed with (case 1 ) and without (case 2 ) the proportion of unaffected colonies; and with weights applied to bleached (x2), partial mortality (x3) and full mortality (x4) (see methods), also with (case 3 ) and without (case 4 ) the proportion of unaffected colonies. Letters show significant groups within each test. 
a

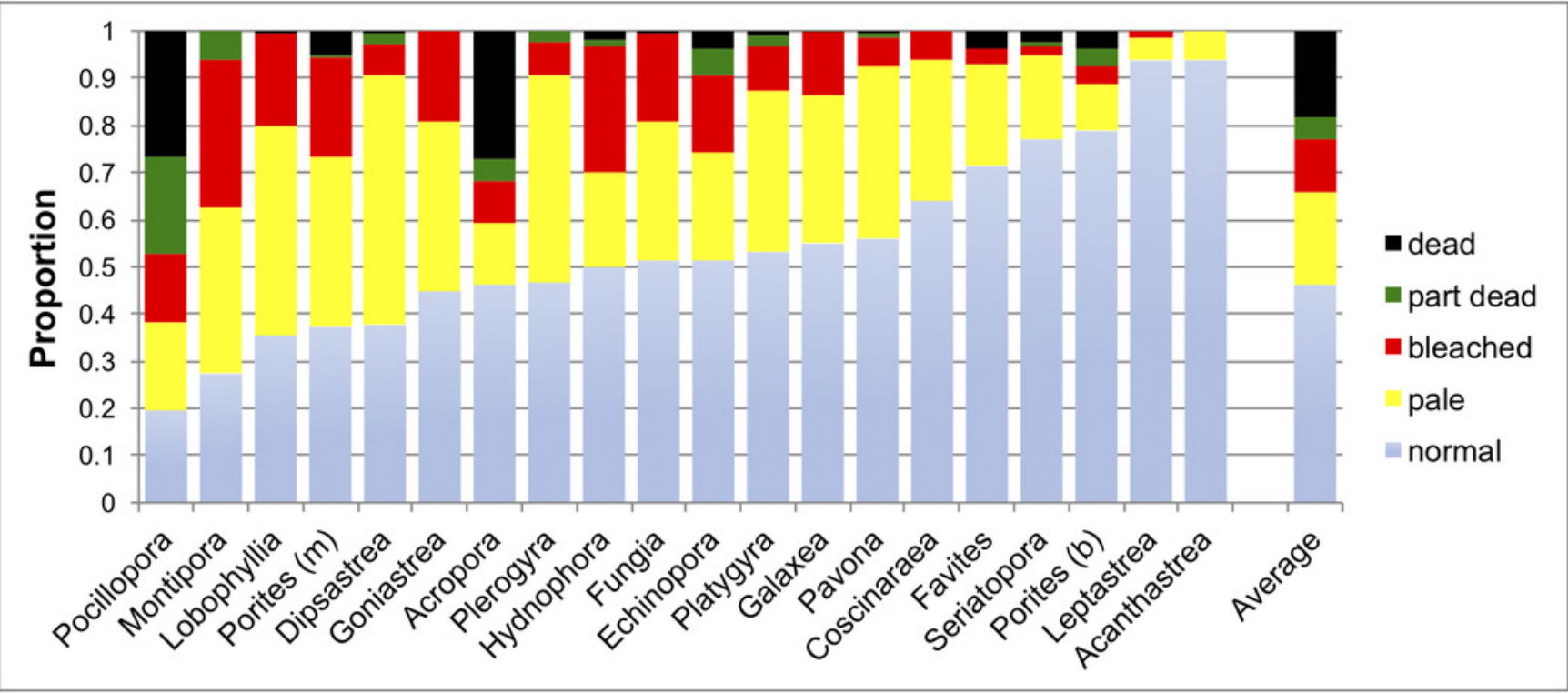

b

c

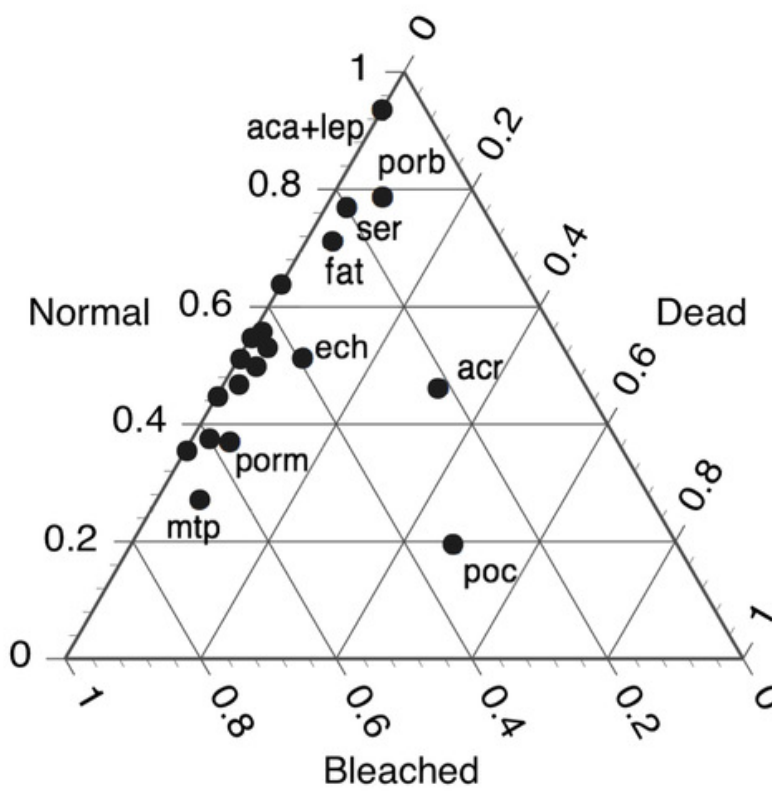

\begin{tabular}{|l|cc|cc|}
\hline \multicolumn{1}{|c|}{ Weights- } & Case 1 & Case 2 & Case 3 & Case 4 \\
\hline nnaffected colonies- & with & no & yes & yes \\
\hline & & & & \\
\hline Pocillopora & a & a & a & a \\
Acropora & a & a & a & a \\
\hline Montipora & b & b & b & a \\
Porites (m) & b & b & b & a \\
Echinopora & b & b & b & a \\
Lobophyllia & b & b & b & a \\
Hydnophora & b & b & b & a \\
Goniastrea & b & b & b & a \\
Dipsastraea & b & b & b & a \\
Fungia & b & b & b & a \\
Plerogyra & b & b & b & a \\
Platygyra & b & b & b & a \\
Galaxea & b & b & b & a \\
Pavona & b & b & b & a \\
Coscinaraea & b & b & b & a \\
\hline Porites (b) & c & b & c & a \\
Favites & c & b & c & a \\
Seriatopora & c & b & c & a \\
Leptastrea & c & c & d & b \\
Acanthastrea & c & c & d & b \\
\hline & & & &
\end{tabular}




\section{Figure 6}

Bleaching and mortality of corals, by colony size.

a) Size class distributions of corals from all sites sampled, by number of colonies (left axis, closed circles) and area (in $\mathrm{m}^{2}$ ) of colonies (right axis, open triangles) per $100 \mathrm{~m}^{2}$ of reef area.

b) Overall bleaching and mortality proportions by colony area in each size class. Data is combined across all coral genera sampled in Mayotte, in June 2010. 
a

$\rightarrow$ Numbers $\quad-\Delta$ Area
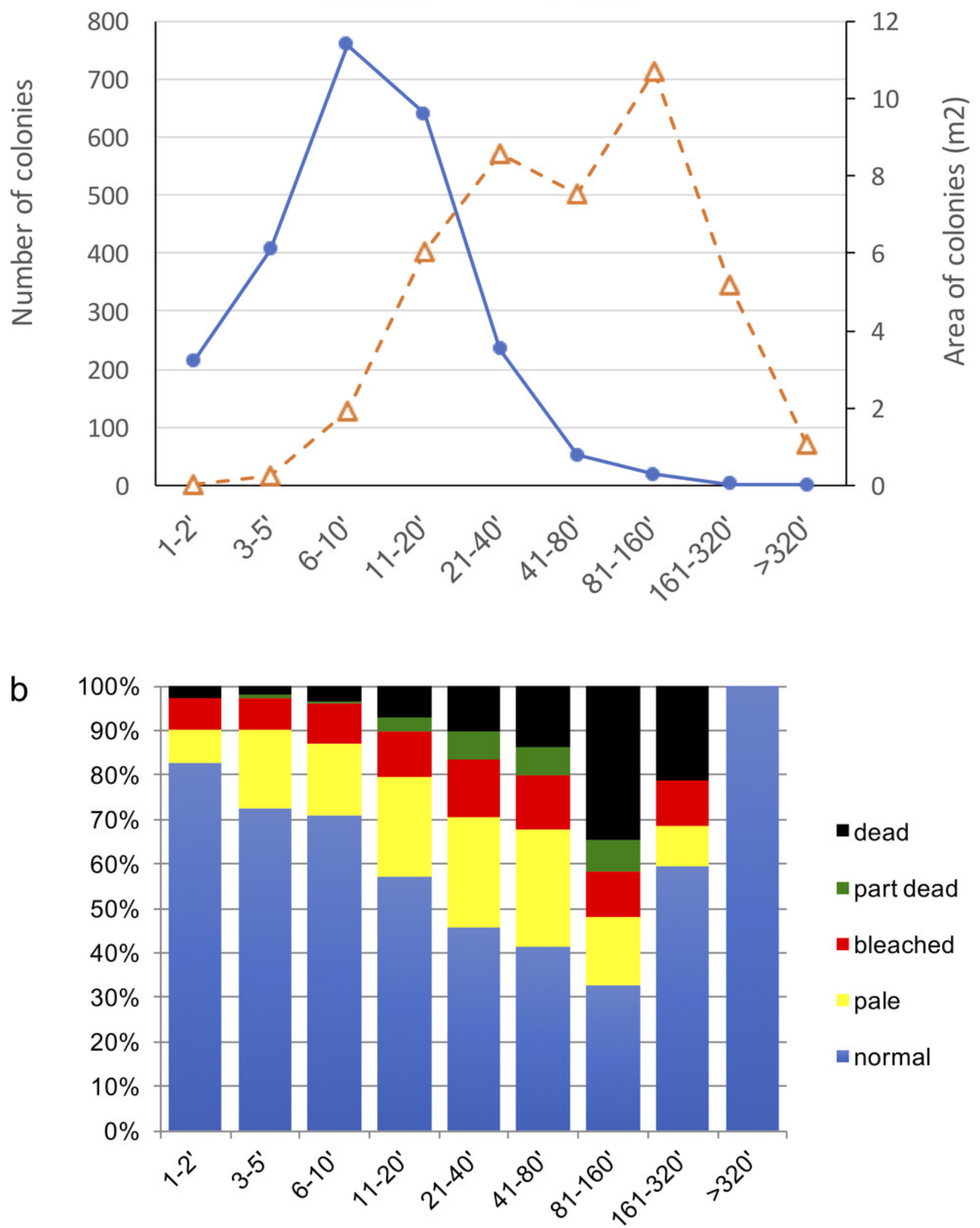


\section{Figure 7}

Estimates of the minimum and maximum impact of the 2010 coral bleaching event on the coral community of Mayotte, 2010.

Size class distribution of all corals by a) abundance and b) area in each size class. The following results are presented for the key taxa Acropora, Pocillopora, Porites (massive species) and other genera combined: c) estimated maximum percentage loss of corals, by number and area of colonies; $d-g$ ) estimated minimum and maximum percentage loss by area in each size class; h) estimated maximum percentage loss of corals by size class. Legend in plot a applies to plots $b$ and $d-g$.

a

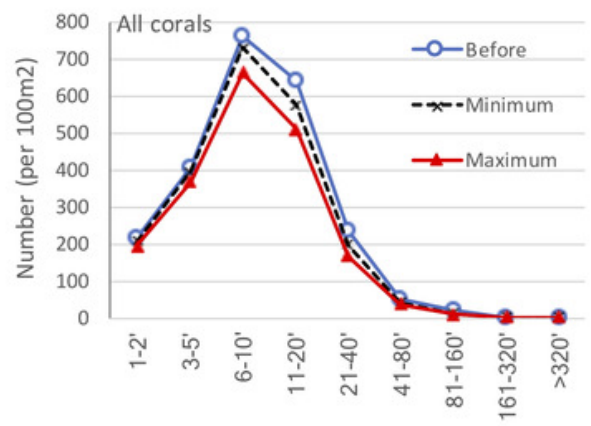

d

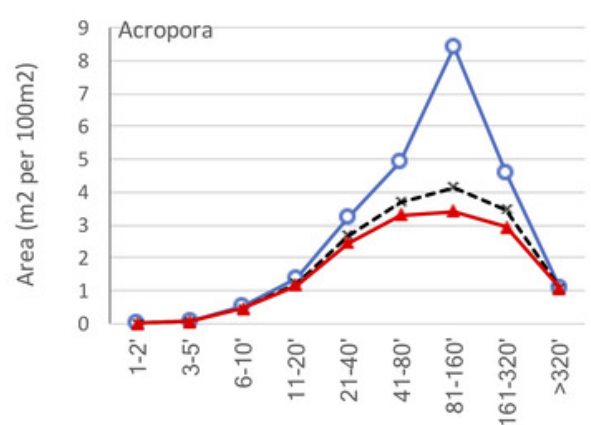

b

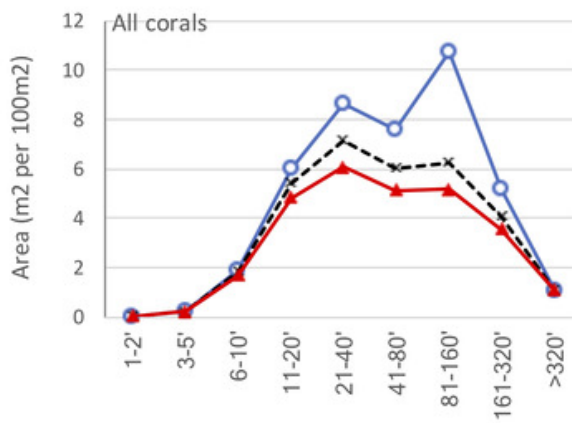

e

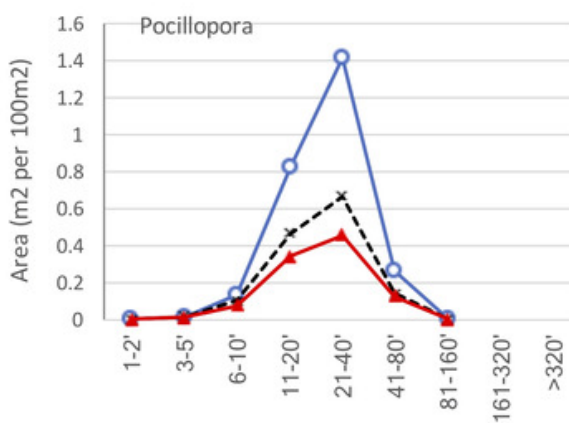

g

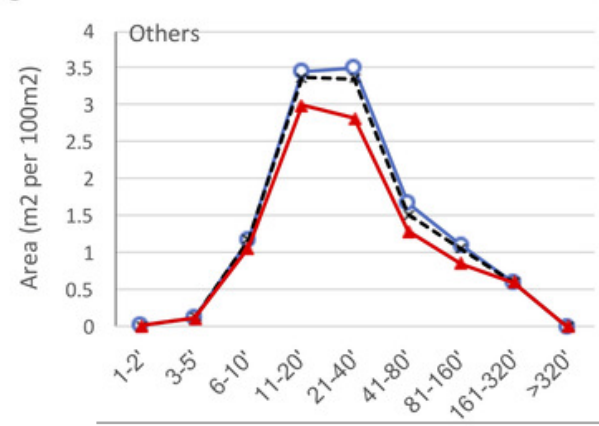

h

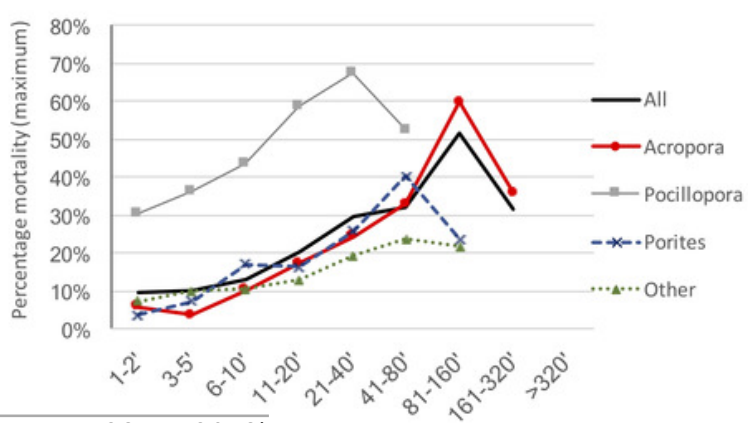

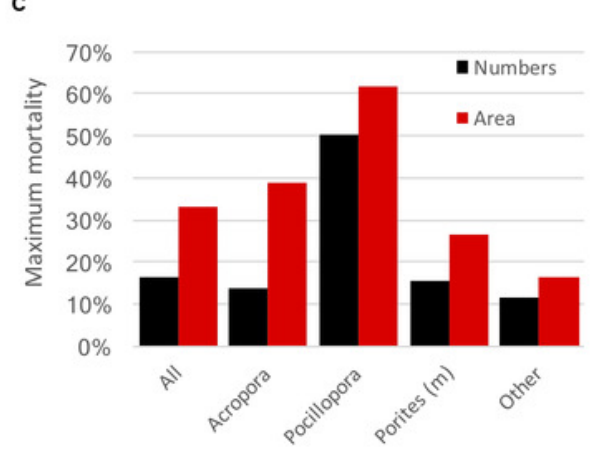

f

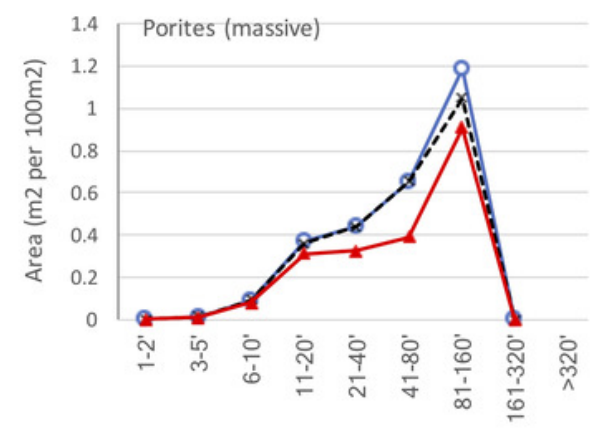




\section{Table $\mathbf{1}$ (on next page)}

Sampling details of Tara Oceans Expedition to Mayotte, 2010.

The table shows the depth characteristics of each site, the area of small coral quadrats and large coral transects samples, actual number of coral colonies counted, and standardized number and area of colonies (to $100 \mathrm{~m}^{2}$ ). 
1 Table 1. Sampling details of Tara Oceans Expedition to Mayotte, 2010. The table shows the

2 depth characteristics of each site, the area of small coral quadrats and large coral transects

3 samples, actual number of coral colonies counted, and standardized number and area of

4 colonies (to $100 \mathrm{~m}^{2}$ ).

\begin{tabular}{|c|c|c|c|c|c|c|c|}
\hline \multirow[t]{2}{*}{ SITE } & \multirow[b]{2}{*}{ Zone } & \multirow[b]{2}{*}{ Depth } & \multicolumn{2}{|c|}{ Area sampled $\left(\mathrm{m}^{2}\right)$} & \multirow{2}{*}{$\begin{array}{l}\text { \# colonies } \\
\text { counted }\end{array}$} & \multicolumn{2}{|c|}{ Standardized to $100 \mathrm{~m}^{2}$} \\
\hline & & & $<10 \mathrm{~cm}$ & $>10 \mathrm{~cm}$ & & \# colonies & area $\left(\mathrm{m}^{2}\right)$ \\
\hline MA05 & bank & 20 & 3 & 12 & 132 & 1625 & 68.5 \\
\hline MA24 & bank & 20 & 6 & 25 & 97 & 527 & 89.0 \\
\hline MA03 & outer barrier & 10 & 3 & 13 & 299 & 5691 & 59.8 \\
\hline MA14 & outer barrier & 10 & 3 & 10 & 242 & 3983 & 48.4 \\
\hline MA15 & outer barrier & 9 & 5 & 20 & 347 & 2980 & 30.8 \\
\hline MA16 & outer barrier & 10 & 5 & 22 & 303 & 2366 & 75.2 \\
\hline MA18 & outer barrier & 10 & 3 & 12 & 338 & 5467 & 70.5 \\
\hline MA22 & outer barrier & 11 & 6 & 25 & 208 & 1529 & 42.8 \\
\hline MA27 & outer barrier & 16 & 6 & 25 & 217 & 1349 & 30.7 \\
\hline MA28 & outer barrier & 16 & 6 & 25 & 328 & 2832 & 19.6 \\
\hline MA29 & outer barrier & 12 & 6 & 25 & 315 & 2666 & 20.2 \\
\hline MA30 & outer barrier & 12 & 6 & 25 & 357 & 2644 & 24.4 \\
\hline MA19 & channel & 10 & 5 & 20 & 256 & 2165 & 27.0 \\
\hline MA08 & inner barrier & 10 & 4 & 20 & 341 & 3045 & 40.2 \\
\hline MA10 & inner barrier & 10 & 3 & 11 & 248 & 4824 & 36.7 \\
\hline MA32 & Inner barrier & 6 & 6 & 25 & 186 & 1175 & 90.3 \\
\hline MA12 & double barrier & 8 & 4 & 15 & 173 & 1923 & 27.6 \\
\hline MA13 & double barrier & 10 & 3 & 10 & 190 & 2880 & 47.6 \\
\hline MA04 & inner & 10 & 4 & 20 & 246 & 2430 & 43.8 \\
\hline MA06 & inner & 10 & 5 & 20 & 305 & 2665 & 72.6 \\
\hline MA07 & inner & 10 & 5 & 20 & 361 & 2945 & 41.0 \\
\hline MA17 & inner & 9 & 6 & 25 & 208 & 1351 & 17.9 \\
\hline MA20 & inner & 8 & 6 & 25 & 218 & 1404 & 48.2 \\
\hline MA23 & inner & 11 & 6 & 25 & 170 & 1643 & 22.4 \\
\hline MA25 & inner & 10 & 6 & 25 & 513 & 3673 & 36.4 \\
\hline MA26 & inner & 11 & 6 & 25 & 236 & 1932 & 10.5 \\
\hline MA34 & inner & 9 & 12 & 50 & 308 & 1028 & 31.3 \\
\hline MA01 & fringe & 10 & 2 & 7 & 112 & 2243 & 41.5 \\
\hline MA02 & fringe & 10 & 6 & 25 & 144 & 1083 & 14.2 \\
\hline MA09 & fringe & 10 & 6 & 25 & 209 & 1710 & 13.0 \\
\hline MA11 & fringe & 8 & 5 & 23 & 144 & 1049 & 32.2 \\
\hline MA21 & fringe & 8 & 6 & 25 & 231 & 1076 & 25.8 \\
\hline MA31 & fringe & 7 & 6 & 25 & 173 & 1135 & 28.8 \\
\hline MA33 & fringe & 4 & 6 & 25 & 284 & 2073 & 74.3 \\
\hline & & & $\begin{array}{l}\text { Totals } \\
176 \\
\end{array}$ & 730 & 8439 & $\begin{array}{r}\text { Averages: } \\
2327 \\
\end{array}$ & 41.3 \\
\hline
\end{tabular}

5

6 